\title{
MICHAEL FARADAY: DE ENCUADERNADOR A HOMBRE DE CIENCIA
}

\begin{abstract}
"Entre más estudiamos el trabajo de Faraday con la perspectiva del tiempo, más nos impresionamos con su insuperable talento como experimentador y filósofo natural. Cuando consideramos la magnitud y extensión de sus descubrimientos y su influencia en el progreso de la ciencia y la industria, no existen honores suficientemente grandes de rendir a la memoria de Michael Faraday -uno de los más grandes descubridores científicos de todos los tiempos".
\end{abstract}

Ernest Rutherford

Físico Inglés-(1931)

* Ingeniero Químico de la Universidad del Valle. Profesor Titular de la Escuela de Ingeniería Química - Facultad de IngenieríaUniversidad del Valle.

\author{
Simon Reif Acherman*
}

\section{RESUMEN}

La historia de la vida de Michael Faraday abarca diferentes aspectos que van desde una infancia prácticamente anónima hasta la consolidación de un prestigio e inmejorable reputación como hombre de ciencia. Además de su ampliamente difundida labor científica, se destacan, entre otras, facetas poco conocidas de él como su sencilla pero definida personalidad, sus profundas convicciones religiosas y unas excelentes habilidades como conferencista y divulgador del conocimiento para públicos de todo nivel. 


\section{ABSTRACT}

The history of Michael Faraday's life covers different aspects from a practically anonimous childhood until the consolidation of a good name and the best reputation as a science man. This paper presents not only his widely known scientific labor but also other less known features as a simple and well definited personality, his profound religious convictions, and excellent skills as lecturer and divulger of knowledge to all people.

El nombre de Michael Faraday es asociado por estudiantes de ciencia e ingeniería, y por profesionales en estas áreas, con los muy conocidos descubrimientos de las rotaciones electromagnéticas, la inducción electromagnética, el benceno y las leyes de la electroquímica (además de otros trabajos menos renombrados, pero no menos importantes), actividad toda que contribuyó a la formulación de los principios fundamentales de los actuales motor eléctrico, transformador, dínamo, para citar sólo algunos ejemplos.

Tal fue el prodigio de su producción científica y la diversidad de sus habilidades, que los químicos modernos, no menos que los físicos, ingenieros y especialistas en metalurgia y en general en investigación de materiales, lo miran como uno de los fundadores de sus respectivos campos de trabajo. Incluso, no resulta exagerado decirlo, que algunas de las áreas de la ciencia y la tecnología actuales deben su propia existencia al trabajo de este pionero. Pocos nombres permanecen tan alto en la apreciación del mundo científico, y son encontrados más frecuentemente por los estudiantes del primer año de educación universitaria como el de Michael Faraday. Él legó a la posteridad un mayor cuerpo de logros científicos puros que cualquier otro hombre, y las consecuencias prácticas de sus descubrimientos han influenciado profundamente la naturaleza de la vida civilizada, a través de desarrollos tecnológicos de gran difusión, y hoy en día tan familiares, como el teléfono, el transistor, los chips de computadores, el generador para vehículos, entre muchos otros.

Los textos de física y química, en particular, no sólo lo relacionan con estos temas de interés, sino que algunos se refieren a él como "el padre de la electricidad"; otros, al enfocar su teoría de los campos de fuerza, lo identifican con el concepto que se constituyó en la piedra clave de las modernas teorías electromagnética y de la relatividad, las cuales a su vez dieron apertura al entendimiento de la realidad física del universo en el siglo pasado; mientras que no pocos lo definen como "uno de los más grandes filósofos experimentales de todos los tiempos". Sin embargo, estos mismos textos, en su gran mayoría, no llegan mucho más lejos que a unas aisladas y por lo general inconexas y breves referencias históricas de su trabajo. Pero, quién fue este hombre al que, por ejemplo, Albert Einstein se refirió como "el responsable, en conjunto con James Clerk Maxwell, del más grande cambio en los fundamentos teóricos de la física desde la época de Mewton"?.

Las personas que por diferentes motivos $y$ circunstancias hemos tenido la oportunidad de tener acceso a algunos materiales relacionados con la historia de la ciencia y tecnología, debemos sentirnos más que satisfechos de poder disfrutar (y obviamente aprender a través de las respectivas lecturas) del apasionante y a veces mágico recorrido por la vida y obra de diferentes hombres de ciencia, ubicarlos en el contexto del desarrollo intelectual de su época, y entender la proyección de su trabajo y contribuciones en el desarrollo de diversas teorías y el progreso de la humanidad.

El caso de Faraday es uno de los ejemplos más representativos en esta dirección. Sin embargo, la falta de motivación existente hacia este 
enfoque, debida más -a juicio personal del autoral desconocimiento y una equivocadamente estrecha e inapropiada distribución del espectro de la información que se considera debe ser adquirida y asimilada por el principiante en estas áreas de estudio, ha conducido a que nuestros estudiantes se priven del acceso a esta clase de información que constituiría, sin duda, un aporte fundamental a su formación integral desde un punto de vista académico y profesional.

El propósito de este artículo es mostrar aspectos poco conocidos para el lector en general de su "formación" como hombre de ciencia, su método de investigación, su relación con otros personajes de su generación, la incidencia que pudieron o no haber tenido en su trabajo aspectos como el religioso, el social y el político, y la dedicación, casi obsesiva, que tuvo principalmente por su trabajo experimental, pero también por su actividad docente y de divulgación científica, así como la influencia de su obra en el trabajo de la ciencia y tecnología posteriores a él, hechos, todos estos juntos, que han permitido catalogar sus aportes como sólo comparables a los de Darwin y Maxwell en su misma época y presentarlo como una de las personalidades más importantes en los anales de la ciencia.

\section{Los Primeros Años:}

Michael Faraday, el tercer hijo de un herrero trabajador, nació el 22 de Septiembre de 1791 en Mewington Butts, en las afueras de Londres. Sus padres se habían trasladado sólo recientemente a esa ciudad, provenientes de Westmorland, debido a la recesión económica. Las condiciones económicas familiares eran precarias, y debido principalmente a ello su educación fue extremadamente simple (casi sin alcanzar lo que hoy entendemos como formación de primaria), con poco más que unos simples rudimentos de lectura, escritura y aritmética. Este es un momento apropiado para empezar a resaltar algunas de las características que diferencian la carrera de Faraday de las de muchos científicos, y que hacen de ella una historia más que interesante de conocer y divulgar.

La primera de estas características, y tal vez una de las más importantes, es que estos rudimentos escolares se constituyeron en toda la educación formal de la que dispuso a lo largo de su vida, adicional solamente a una serie de conferencias divulgativas a las que periódicamente asistió años después, y a las que haremos referencia más adelante. Faraday tuvo prácticamente muy poco más que una elemental formación matemática, lo que se refleja claramente en sus más de cuatrocientos cincuenta publicaciones (!), en las que en ninguna de ellas aparece una simple ecuación diferencial, más por no necesitarlas que por el hecho de desconocerlas, lo que destaca su capacidad como poco menos que admirable. Sin embargo, el hecho de no saber de matemáticas, lo que en la mentalidad de muchos científicos actuales podría llevar a pensar sus logros como casi increíbles, es tal vez lo que contribuyó más decididamente a su inspiración. Al hacer referencia a este hecho, Maxwell destacaba que "el cálculo es sólo una parte de las matemáticas", y, de acuerdo con él, Faraday fue "en realidad, un matemático de un muy alto grado -uno a partir del cual los matemáticos del futuro podrán derivar métodos valiosos y fértiles". A juicio de diversos intérpretes, esta aparente deficiencia formativa lo obligó a desarrollar, por ejemplo, un simple concepto no matemático mientras buscaba una explicación a los resultados de sus experimentos en fenómenos eléctricos y magnéticos. Su deducción de la teoría de campos ilustra, más que un maquillaje por su falta de formación académica, dos cualidades muy importantes: su fantástica intuición y la independencia y originalidad de su manera de pensar.

Faraday abandonó su elemental educación escolar a la edad de 12 años, y todo el conocimiento que adquiriría en adelante se debió a su espíritu autodidacta. Un año más tarde obtuvo su primer trabajo como mensajero de un 
inmigrante francés, propietario de una venta de libros y una encuadernadora. Al poco tiempo inició un aprendizaje como encuadernador en el mismo negocio, labor en la que permanecería por espacio de siete años. Durante este lapso, Faraday desarrolló un apasionado interés por los libros que caían en sus manos, por virtud de su misma actividad, teniendo allí su primera aproximación con la ciencia. Esos libros lo introdujeron en el mundo fascinante de los fenómenos naturales, induciéndolo a moldear la idea de que ellos obedecían a cierto número de leyes ordenadas de manera divina, las cuales los seres humanos deberían estar en capacidad de comprender. Así surgió su resuelta decisión de estudiar ciencia. Entre los libros que más atrajeron su atención se encontraba uno publicado en 1809 por la esposa de un médico Suizo, Mrs. Marcet, titulado "Conversaciones en Química", y una copia la "Encyclopaedia Britannica", $3^{\text {a }}$ edición, 1797, donde se encontró con un artículo escrito por un controvertido químico de la época, Mr. James Tytler, sobre un tópico que inmediatamente cautivó su interés: la electricidad.

La lectura de éstos y muchísimos libros más, en conjunto con unas conferencias sobre química en la City Philosophical Society, a las que empezó a acudir en 1810, pagando un chelín por cada una (dinero que le suministraba su hermano Robert), dieron inicio a la preparación de Faraday para una carrera científica en una época en que la ciencia ofrecía pocas oportunidades, especialmente para alguien que no poseía riqueza heredada o buenos contactos. En los tiempos de Faraday, a diferencia de lo que comenzaría a suceder muchos años después, eran muy pocos los que estudiaban ciencia en el colegio o la universidad, y menos aún los que seguían una carrera científica.

Guiado por una serie de observaciones respecto al auto-perfeccionamiento en diferentes actividades, tomadas de la lectura de otro de los libros que había llegado a sus manos ("El
Mejoramiento de la Mente", publicado por el escritor Isaac Watt), Faraday comenzó a llevar una especie de cuaderno o "libro de lugares comunes", como él mismo solía llamarlo, en el cual anotaba ideas, hechos, citas y preguntas en la medida en que se le iban ocurriendo. El encabezado de la primera página describe claramente su contenido: "Una colección de Motas, Ocurrencias, Eventos, etc., relacionados con las Artes y las Ciencias, recogidas y coleccionadas de Papeles Públicos, Revistas, Magazines y otros trabajos miscelaneos. Con el propósito de promover tanto el entretenimiento y la instrucción y también de corroborar o invalidar aquellas teorías que se inician continuamente en el mundo de la Ciencia". La escritura de este cuaderno de notas marca el inició tempranero de lo que, más que un hábito, muestra otra de las características más interesantes de su método de trabajo y un aspecto poco frecuente de encontrar, aún en científicos posteriores: el detallado y completo registro de todas y cada una de las observaciones, en el mismo momento en que éstas se iban haciendo, relacionadas con las diferentes facetas de su actividad científica principalmente con su trabajo experimental; a lo que agregaba sus pensamientos inmediatos de lo que, a su juicio, ellas significaban. Esta costumbre se extendería a lo largo de toda su obra. Como resultado de ésto, ha sido posible la publicación de todas sus notas y apuntes en un diario en siete volúmenes, y la realización de un trabajo, aún sin finalizar, que trata de recolectar toda su correspondencia, y que ya alcanza cuatro volúmenes. Esta situación ha sido afortunada para sus biógrafos, y por ende para el público en general, ya que gracias a ello hemos podido construir quizás un retrato más completo de él que de cualquier otro personaje que haya cambiado el curso de la historia en una magnitud comparable.

En 1812 Faraday terminó su aprendizaje y comenzó a trabajar como encuadernador con un hombre al que pronto encontró poco agradable. Por esa misma época, y gracias a un tiquete 
obsequiado por un cliente de su primer empleador, tuvo la oportunidad de asistir a las cuatro últimas conferencias de un curso sobre Química en las instalaciones de la Royal Institution. El conferencista era Humphry Davy, uno de los más renombrados científicos de la época, y quien gracias a su trabajo sobre el aislamiento electroquímico del sodio y el potasio como elementos químicos y a diversas series de charlas divulgativas, ofrecidas desde 1801, había contribuido decididamente al logro de una gran reputación para esta Institución como centro de investigación y sitio de moda para la difusión del conocimiento científico. El encuentro con Davy marcó la carrera científica de ambos, pero principalmente la de Faraday, en diferentes aspectos. Faraday quedó fascinado con las disertaciones de Davy, de las cuales tomó copiosas notas que posteriormente reescribió, agregándole ilustraciones y un índice, para después encuadernarlas personalmente. La asistencia a estas conferencias le ayudó a tomar una decisión definitiva: buscar un trabajo relacionado con la ciencia, actividad que consideraba noble. Como lo explicaría posteriormente, en su propias palabras, "mi deseo era escapar del comercio, el cual consideraba perverso y egoísta, y consagrarme al servicio de la ciencia, pues imaginaba que hacía a sus cultivadores amables y generosos". Su deseo era llegar a ser un filósofo -lo que nosotros llamaríamos actualmente un científicoy en particular, un químico.

Poco tiempo después, faraday envió dichos apuntes a Davy, acompañando una carta en la que le solicitaba estudiar la posibilidad de conseguirle un trabajo en la Royal Institution. Davy quedó muy impresionado con la diligencia y entusiasmo del joven, y aunque en su primera entrevista formal le aconsejó que continuara dedicado a la encuadernación, también le dijo que tendría en cuenta su nombre a la primera oportunidad que se presentara. La oportunidad llegó de manera casual a finales de Octubre, cuando Davy, durante la realización de algunos experimentos con una combinación de nitrógeno y cloro, sufrió graves heridas en los ojos por virtud

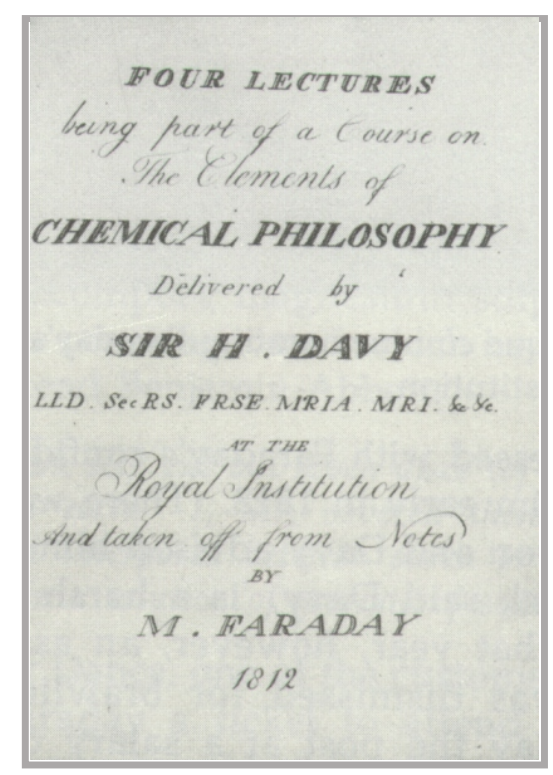

Página de título de las notas de Faraday sobre las conferencias de Davy. -

1812

de una explosión de dicha mezcla. Ante esta situación, que afectaba obviamente de manera notable su trabajo, Davy propuso el nombre de Faraday como su ayudante temporal, actividad en la que éste último se desempeñó de manera parcial, alternándola con su trabajo de encuadernador. La situación se regularizó definitivamente meses después, al sucederse el despido, por razones disciplinarias, del ayudante oficial del laboratorio. Davy, inmediatamente, ofreció el puesto de ayudante de química a Faraday, y éste empezó a ejercer la posición a partir del $1^{\circ}$ de marzo de 1813 , con un salario inicial de 25 chelines semanales. Esta fecha marcó el inició de una relación que llegaría a ser mucho más que laboral entre el entusiasta y talentoso joven y la Institución a la que dedicó el mayor porcentaje de sus esfuerzos, y en la que trabajó prácticamente el resto de su vida. La etapa que se inició en la vida de Faraday a partir de ese mismo momento podría dividirse básicamente en dos partes: la primera, marcada por la muy variable y no poca tormentosa relación suya con Davy y la gran influencia que este último tendría en el desarrollo de su actividad científica, y la segunda, determinada por la desaparición de su tutor y jefe hasta ese 
momento. La ausencia de Davy, fallecido en Mayo de 1829, significaría para Faraday una mayor sensación de libertad, lo que a su vez le permitiría ganar la confianza necesaria para proseguir una carrera independiente.

\section{La Relación Faraday - Davy}

Los primeros seis meses de su vinculación con la Royal Institution significaron para Faraday un arduo e intenso trabajo de aprendizaje de un gran número de diversas técnicas requeridas para su actividad en el laboratorio. Las circunstancias continuaron favoreciéndolo, y en otoño del mismo año fue invitado por Davy a acompañarlo a él y a su esposa en un largo viaje por el continente europeo. El propósito esencial del mismo era permitir a Davy la posibilidad de establecer relaciones y contactos con los principales científicos europeos del momento, objetivo que llegaría a cumplirse plenamente. Si bien, para ese entonces, Inglaterra y Francia se encontraban en guerra, la reputación de Davy y el interés de Mapoleón en la actividad científica hicieron que el proyecto no fracasara, gracias a un pasaporte especial concedido por este último, y en el que se especificaba que sólo Lady Davy, su doncella y un asistente podrían viajar con el eminente científico inglés. El viaje se inició el 13 de Octubre, llevando como parte del equipaje necesario el equipo científico requerido para la realización de los experimentos planeados durante la ruta, y Faraday, quien hasta ese entonces no había tenido la oportunidad de salir de Londres, pudo recorrer a lo largo de dieciocho meses diferentes lugares ubicados en Francia, Suiza, Italia, Alemania y Bélgica. Las obligaciones definidas para él durante el viaje eran las correspondientes a un secretario y asistente científico, aunque debió desempeñar -a regañadientes- otro tipo de deberes más propios de un criado. Esto motivó algún tipo de tensión durante el recorrido, en particular con la esposa de Davy, quien lo trataba como un sirviente más, y a la que Faraday describió como "arrogante y orgullosa en excesivo grado y que disfrutaba haciendo sentir su poder sobre sus inferiores".
El viaje, las diferentes experiencias y los contactos que estableció durante el mismo, constituyeron, de manera obviamente no formal, la educación universitaria de Faraday. Tanto su diario de viaje como su correspondencia indican minuciosamente, no sólo los detalles de su actividad científica, sino también la gran atención con que observaba el paisaje, la gente y las costumbres de las regiones recorridas. En París, con la ayuda de Ampère, Davy y Faraday hicieron un importante descubrimiento al identificar el yodo como un nuevo elemento químico, mientras analizaban las cenizas de algas marinas. Así mismo, en vista de su experiencia con tricloruro de nitrógeno, prepararon el explosivo triyoduro de nitrógeno; asistieron a una conferencia ofrecida por Gay-Lussac y, antes de dejar la ciudad, se reunieron con otros reconocidos eruditos como el astrónomo y físico francés Dominique François Arago, el naturalista y geógrafo alemán Alexander Von Humboldt, y el también naturalista francés y creador de la anatomía comparativa y la paleontología, Georges Cuvier. Así mismo, tuvieron sesiones de trabajo con el extraordinario, pero no menos polémico, físico americano Benjamín Thompson (más conocido como Conde Rumford), quien pocos años antes se había separado de su esposa, la viuda del famoso químico francés Antoine L. Lavoisier.

En la ciudad italiana de Génova estudiaron la descarga eléctrica de una especie de pez denominado torpedo, para tratar de determinar si ella era capaz de descomponer el agua. Sin embargo, los ejemplares con los que trabajaron fueron tan pequeños y débiles que no alcanzaron a obtener resultados perceptibles. El efecto buscado cı $_{1}$ ese entonces resultaba de gran importancia, dado que existía la duda respecto a si la electricidad animal era igual a la obtenida a partir de ntras fuentes (en 1833 Faraday volvería a embarcarse en este asunto y lograría demostrar dicha identidad). Posteriormente se desplazaron a Florencia, en donde permanecieron poco más de veinte días. Allí, y con la ayuda de los grandes lentes que formaban parte del equipo de 
laboratorio de la "Accademia del Cimento", se dieron a la tarea de experimentar con la combustión del diamante, material cuya naturaleza había intrigado a los químicos por más de medio siglo. El problema surgía del hecho de que el único producto detectable de la combustión era dióxido de carbono, lo cual a su vez indicaría que el diamante estaba compuesto de carbono puro. Si esto era así, de qué estaba compuesto entonces el carbón mineral negro ordinario?. Resultaba en ese momento imposible de creer que sustancias tan diferentes en sus propiedades físicas y químicas como el carbón vegetal y el diamante, pudieran ser la misma en esencia. Los resultados de estos experimentos y otros posteriores, realizados en Roma, le permitirían a Davy aceptar, en un artículo publicado poco tiempo después, el punto de vista de que el diamante, el grafito, el carbón vegetal y el mineral eran todos esencialmente carbono en diferentes formas cristalinas.

Posteriormente visitaron Vesuvius, se familiarizaron con el trabajo de Volta en Milán, y Faraday incluso escribió algunas breves notas sobre un animal que llamó su atención: la luciérnaga. En el transcurso de su recorrido, y más específicamente en Roma, Davy y Faraday participaron de un experimento en el que se pretendió identificar una conexión por mucho tiempo buscada entre la luz y el magnetismo. Si bien el experimento no tuvo éxito y ambos, en consecuencia, no quedaron convencidos de la existencia de dicha relación, este tipo de actividades, en conjunto con muchas otras, fueron sembrando en Faraday inquietudes acerca de los que más adelante serían temas centrales de su investigación científica. Aunque en su diario Faraday sólo hace referencia a detalles generales de los lugares recorridos, las relaciones establecidas y los experimentos llevados a cabo, en una carta dirigida a uno de sus mejores amigos, Benjamín Abbott, cuestiona su decisión de haberse embarcado en dicho viaje. Aún reconociendo las ventajas que esta experiencia le brindaba, en términos del gran volumen de conocimientos adquiridos durante la misma,
Faraday da rienda suelta a su profundo malestar por las continuas humillaciones por parte de Lady Davy. Este desagrado cada vez mayor, al punto que ya él se resistía a aceptar calladamente los insultos, podría haber sido uno de los factores determinantes para que Davy tomara la decisión de dar por finalizado el viaje. El otro elemento podía ser el hecho de que en Febrero de 1815 Mapoleón había escapado de su destierro en la Isla de Elba, y al recuperar su poder amenazaba de nuevo a Europa. El hecho es que a mediados de abril los viajeros iniciaron su regreso a Inglaterra, prácticamente dos meses antes de que el Emperador francés, al mando de sus tropas, sufriera la derrota definitiva en Junio 18 en Waterloo, a manos de las fuerzas aliadas a ordenes del Duque de Wellington.

La gran aventura había terminado. Faraday, el hombre que pisó nuevamente suelo inglés en la primavera de 1815 era muy diferente a aquel que había partido de allí en 1813. Había visto una parte del mundo, se había dado cuenta de su complejidad y diversidad, y había aprendido mucho sobre las actividades y el comportamiento de los seres humanos. Había, así mismo, conocido algunos de los más destacados científicos del momento, y si bien se había impresionado con ellos, ellos también se impresionaron con él. Junto a Davy había logrado su entrada a una sociedad cuya aceptación, sin embargo, era de poca importancia en su cada vez más madura manera de pensar. A diferencia de Davy, él ya tenía muy claro que nunca se alejaría de la búsqueda de la verdad por correr detrás de una ilusa y artificial vida en los salones elegantes de la alta sociedad. Durante el viaje, Faraday había sido testigo de cómo la gran reputación y relaciones públicas de su jefe habían incidido en la posición preponderante que éste tenía en la ciencia europea. Así mismo, se había dado cuenta también, tristemente para él, que los muy merecidos homenajes a su maestro habían conducido, quizás, a un deterioro en aquellas cualidades que, a su juicio, deberían acompañar la eminencia intelectual. Este contraste de personalidades se iría acentuando cada vez más 
con el transcurso de los años. Mo obstante proceder igualmente de un medio pobre, Davy había disfrutado a fondo de todas las ventajas sociales y económicas que pudo capitalizar gracias a su éxito en la actividad científica. Se movía en las esferas de la alta sociedad, fue nombrado Caballero y recibió el titulo de Barón, se casó con una viuda rica y había ido descuidando paulatinamente su investigación en ciencia. Su prepotencia lo había vuelto superficial y desconsiderado. Lo que Faraday interpretaba como corrupción en las actitudes de Davy, fue una lección para él en su manera de ser, la cual se guiaba por el precepto bíblico relacionado con no acumular riquezas en la tierra. Esto, sin embargo, no significaba aceptar la pobreza, sino vivir de manera cómoda pero sencilla.

Volviendo a la historia, en Mayo de 1815 Faraday reasumió sus actividades en la Royal Institution, ocupando ahora el cargo de "Ayudante y Superintendente de los Equipos del Laboratorio y la Colección de Minerales", con un salario más razonable de 30 chelines por semana. Además, se le concedieron dos habitaciones en el piso superior de la edificación para su propia vivienda. La carrera del gran científico iniciaba su despegue definitivo. Si bien por razones obvias de espacio este artículo no pretende dar información detallada sobre sus contribuciones científicas, resulta inevitable y más que eso, indispensable, hacer referencia, al menos superficial, a algunas de ellas, para situar al lector en el contexto general de la historia.

Faraday desempeñó el puesto de ayudante de química durante los diez años siguientes, período en el cual dedicó gran parte de su tiempo a colaborar con diferentes conferencistas de la Royal Institution en sus demostraciones, además de dictar clases de química a estudiantes de medicina y otras carreras que necesitaban aprender la materia. Durante esta época aprendió numerosas y diversas técnicas necesarias para el trabajo de un químico experimental: soplado de vidrio, construcción de aparatos, peso exacto de muestras y valoración, entre muchas otras. El mantuvo la utilización de estas técnicas a lo largo de toda su carrera, además de incrementar paulatinamente su número y diversidad en la medida en que iba interesándose en otras áreas científicas. Los laboratorios de la Royal Institution eran, por esa época, unos de los mejores equipados de la Gran Bretaña, lo que no le impedía, sin embargo, gastar, de su propio dinero, en no pocas ocasiones, para la compra de nuevos elementos, si ellos se hacían necesarios. Poco a poco fueron aflorando en él dos cualidades difíciles de encontrar simultáneamente en muchos científicos: era un investigador brillante que combinaba eficazmente la habilidad manual y su extraordinaria destreza práctica con un alto grado de originalidad en su manera de pensar y una notable creatividad mental en el diseño de nuevos aparatos y en la realización de nuevos experimentos.

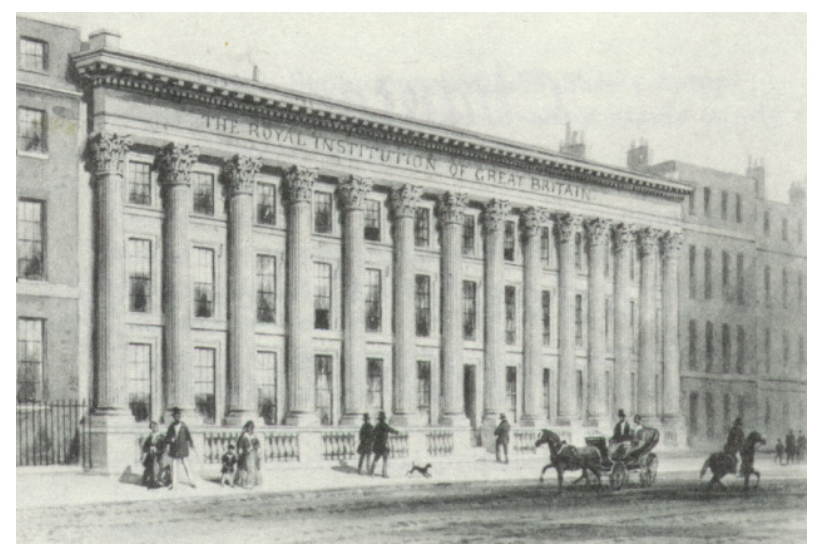

Fachada de la Royal Institution, desde 1799

En la medida en que iba adquiriendo toda esta suerte de habilidades, Faraday empezó a colaborar más y más en diferentes investigaciones, y a realizar análisis químicos rutinarios, bajo la supervisión de los mismos conferencistas. Por esa misma época -1815empezó a hacer investigaciones casi independientes, principalmente en química, fruto de una de las cuales publicó al año siguiente su primer artículo sobre el tema del análisis de la cal viva de Toscana; y dio inicio a su brillante faceta 
como conferencista, al ofrecer su primer ciclo de charlas sobre temas diversos en la City Philosophical Society, poco después de ser elegido como uno de sus miembros.

La carrera de Faraday, quien continuaba como ayudante de Davy, permanecía aún eclipsada en buena medida por el famoso científico. Además de un tipo de labores alternas que también le habían sido asignadas, relacionadas con la ayuda que debía prestar a las actividades editoriales del "Quarterly Journal of Science", publicado en la Royal Institution, y las ya detalladas anteriormente, su trabajo era por ese entonces algo rutinario, y se reducía, en un alto porcentaje, a la colaboración con Davy en los temas que para este último eran de interés, como el perfeccionamiento de la lámpara de minero y el estudio de la utilidad de forrar el casco de los buques con planchas de cobre (técnica que después se perfeccionaría exitosamente para prevenir la corrosión en este medio de transporte), y aún como su representante personal en diferentes tipos de negocios, cuando el renombrado científico inglés se encontraba fuera del país. La única manera de hacerse a un nombre y una reputación propia era consiguiendo un descubrimiento independiente e importante. La oportunidad se presentó en 1821 (el mismo año en que fue nombrado como superintendente de la casa en la Royal Institution y en el que se casó con Sarah Barnard -hija de un próspero trabajador de la plata, y a quien conoció en la casa de reuniones de los sandemanianos, comunidad religiosa a la que ambos pertenecían-) y él la aprovechó perfectamente. La comunidad científica estaba muy impresionada por el anuncio hecho un año antes por el físico Danés Hans Christian Oersted sobre su descubrimiento de la existencia de una relación entre la electricidad y el magnetismo. Él había encontrado que una corriente continua en un alambre causaba una deflexión de una aguja magnética próxima. Oersted sugirió que un campo magnético rodeando el alambre conductor actuaba en círculos alrededor y perpendicular a él. Al año siguiente el científico francés André-
Marie Ampère sustituyó la aguja magnética por otro alambre conductor de corriente, y encontró una fuerza, igualmente magnética, de atracción o repulsión entre los dos alambres, dependiendo de la dirección del flujo de corriente.

Davy y Faraday, aunque absortos en sus investigaciones químicas, se interesaron rápidamente en los nuevos descubrimientos electromagnéticos, y llevaron a cabo algunos experimentos para su propia satisfacción. Al mismo tiempo, el renombrado científico inglés Willian Hyde Wollaston (quien posteriormente, y en otra área de la ciencia, ejercería una considerable influencia en la aceptación de la teoría atómica de Dalton) sugirió a Davy la posibilidad de que el campo magnético podría producir rotación. Faraday interpretó ésto como la rotación de un alambre alrededor de su propio eje. Durante los meses siguientes continuó trabajando, ya en solitario, y poco después, en el verano de 1821 , a petición de un amigo próximo, el editor de "Annals of Philosophy", escribió y publicó allí un artículo (su único papel anónimo) "Historical Sketch of Electromagnetism" ("Descripción histórica del electromagnetismo"). Allí, Faraday resumía críticamente la evidencia experimental y las especulaciones teóricas que existían en esta floreciente área de investigación. El trabajo continuó alrededor de este tema, y Faraday llevó a cabo numerosos experimentos (algunos de los cuales fracasaron, entre los cuales debe mencionarse uno diseñado para contrastar la hipótesis de Wollaston). Durante este proceso observó que un alambre que transportaba corriente giraba continuamente alrededor del polo de un imán. Faraday se apresuró a publicar el anuncio de estos "nuevos movimientos" tan sorprendentes, a partir de allí denominados rotaciones electromagnéticas, las cuales constituyen el principio del motor eléctrico.

La publicación del artículo dio lugar, sin embargo, a una serie de acontecimientos que pusieron en tela de juicio su honor y honestidad. 
Unos amigos de Davy lo acusaron de no reconocer debidamente la contribución de éste, y de haber utilizado la idea de Wollaston sin dar el crédito correspondiente. Realmente Faraday había interpretado equivocadamente la sugerencia de Wollaston, y la historia se ha encargado de verificar que sus experimentos y hallazgos siguieron una línea de pensamiento muy personal y original, que lo condujeron incluso a una solución bastante diferente a la de quien pretendían sugerir había simplemente copiado. Wollaston, por ese entonces Presidente interino de la Royal Society, no presionó la reclamación y la disputa no pasó a mayores ni alcanzó a ser de conocimiento público, al menos en ese momento. Faraday, sin embargo, se esforzó por todos los medios en dejar en limpio su nombre, y lo único que quedó a nivel personal como conclusión es que sus relaciones con Davy se resquebrajaron en forma apreciable. A nivel científico, lo más importante a destacar es el descubrimiento y cómo éste le permitió rápidamente ganar renombre a nivel internacional. Él recién había ingresado en el terreno de la ciencia electromagnética; antes habían sido descubiertos muchos fenómenos fundamentales tales como las atracciones y repulsiones eléctricas y magnéticas, y la corriente eléctrica y sus efectos; ya se tenía conocimiento de los trabajos de Coulomb y Poisson y los experimentos con resultados no publicados de Cavendish, quienes al seguir el camino marcado por Mewton y hacer de las fuerzas que actúan entre los cuerpos su principal objeto de estudio, habían fundamentado las teorías matemáticas de las fuerzas eléctricas y magnéticas. Después, como ya lo mencionamos, aparecieron las figuras de Oersted y Ampère. La así llamada rotación electromagnética, que habilitó a Faraday a imaginar un posible primitivo motor eléctrico, podía también ocurrir en el campo magnético de la tierra, un hecho que él demostró emocionadamente a su esposa el 25 de Diciembre de 1821. Ese descubrimiento indicaba claramente su capacidad para llevar a cabo una investigación destacada en un campo nuevo y apasionante. Además de ser su primera contribución importante en el campo del electromagnetismo, las rotaciones constituyeron así mismo la primera pincelada en un nuevo retrato de la naturaleza, el cual se iría completando durante los treinta años siguientes. Ese retrato sería el resultado de la conjunción de varios factores adicionales pero muy relacionados con su actividad estrictamente experimental, los cuales dan una luz considerable sobre el hombre y su obra, y entre los que podemos mencionar la estrecha relación existente para él entre ciencia y religión, su recurrente preocupación por comprender el mundo natural como una entidad de creación divina, y la forma en que su pensamiento y acción se combinaron para crear situaciones en que la naturaleza pudiera ser analizada profundamente y sus leyes puestas de manifiesto.

La situación de la disputa con Wollaston reapareció, sin embargo, en 1823, en el marco de una nueva querella, cuando Faraday se encontraba experimentando con la licuefacción de gases (inicialmente con cloro), trabajo que llevaría a esclarecer posteriormente el reconocimiento de la existencia de la temperatura crítica. Hasta ese entonces se encontraba muy en boga un punto de vista rígido y errado por el cual se aseguraba que las sustancias se clasificaban en tres categorías claramente distinguibles (sólidos, líquidos y gases) completamente independientes y discontinuas entre sí. Faraday dio el paso inicial para la refutación de esta teoría, al interpretar unos experimentos realizados en 1822 por el Barón Cagniard de LaTour, quien había demostrado que debía existir un límite a la dilatación de un fluido volátil, por encima del cual se convertiría en vapor sin importar la presión. Él concluyó de sus experimentos preliminares en 1823, y de aquellos que realizaría posteriormente de manera interrumpida por espacio de más de dos décadas, que este punto o límite no era uno de "destrucción" del estado líquido, sino uno "en el cual el fluido y su vapor se hacían uno solo de 
acuerdo con la ley de la continuidad". El trabajo de Faraday serviría de base para que en la década de 1860 el físico químico irlandés Thomas Andrews mostrara por primera vez que los estados gaseosos y líquidos son sólo etapas distantes de la misma condición de materia, capaces de transformarse uno en otro por un proceso de cambio continuo, determinándose así el principio de continuidad entre ambos.

Pero volviendo al trabajo preliminar sobre el tema en 1823, si bien la idea original parece haber surgido de la mente de Davy, fue su aún asistente de investigación quien llevó a cabo toda la parte experimental, además del completo análisis de resultados, los cuales incluían algunos completamente opuestos a los previstos por su tutor. Davy, sin embargo, solicitó parte del crédito por este trabajo, a lo que Faraday se negó. Entonces circuló el rumor según el cual Davy había repetido la acusación a su asistente de copiar ideas de otros en su trabajo de las rotaciones electromagnéticas, sin hacer el reconocimiento debido. Aunque él mismo desmintió posteriormente esa versión, el daño ya estaba hecho, y Faraday se vio obligado a admitir públicamente la autoría del "Historical Sketch of Electromagnetism" y a escribir su "Historical Statement" ("Declaración Histórica") en la que describía la trayectoria experimental que había seguido para llegar a su descubrimiento, y así defender su primacía en el mismo.

Lo peor de la relación entre los dos hombres de ciencia apenas iba a sucederse. Después de los trabajos adelantados, Faraday era un obvio candidato para ser elegido como miembro de la Royal Society, entidad de la cual Davy era entonces Presidente. En efecto, poco tiempo después fue nominado para ello, sin consultar previamente a Davy, como era la costumbre, lo cual irritó notablemente a este último, quien decidió oponerse a la elección. Históricamente se han mencionados diversas conjeturas tendientes a explicar esta actitud. La mayoría se inclinan por aceptar la hipótesis en virtud de la cual Davy, a quien preocupaban mucho las opiniones ajenas, quería evitar el hecho de que se pensara que él continuaba manteniendo la tradición de anteriores Presidentes de la Institución en el sentido de hacer uso indebido del cargo para admitir a sus amigos y oponerse a sus enemigos, independientemente de su correspondiente mérito científico. Él pensaba que si apoyaba la elección, podría interpretarse que lo hacía dada la estrecha relación de trabajo existente entre ambos por espacio de varios años. Aún habiendo sido éste el motivo, la sensación que ha permanecido desde esa época es que Davy nunca pudo aceptar de buena manera el ascenso vertiginoso en la carrera de su ayudante, en tanto que su propia labor investigativa declinaba. De cualquier manera, la elección de Faraday se dio en Enero de 1824. Si bien en lo personal la relación entre ambos estaba ya prácticamente rota, en el aspecto profesional aún continuó. En su calidad de Presidente de la Royal Society y superior de Faraday en la Royal Institution, Davy poseía aún suficiente poder como para ejercer una influencia considerable sobre su trabajo y su carrera. Pasó de ser el benevolente patrón de Faraday a explotar sus habilidades en diferentes proyectos, sin preocuparse, aparentemente, de si esas actividades iban en detrimento de la carrera de su, hasta poco antes, protegido. Un ejemplo de ellas es su trabajo en el perfeccionamiento de la calidad del vidrio para telescopios y otros instrumentos ópticos, actividad a la que Faraday dedicó, con innegable disgusto por ser ajena a sus verdaderos intereses, gran parte de su tiempo por espacio de dos años, y de la que el único beneficio que sacaría sería el de disponer de una pieza de material apropiado para el descubrimiento del efecto magnético-óptico (posteriormente denominado efecto Faraday) hacia finales de 1845.

En 1825 fue ascendido al cargo de Director del Laboratorio de la Royal Institution con sueldo de 100 libras anuales. Al año siguiente se le liberó de su obligación de ayudar a otros conferencistas en 
sus demostraciones, y emprendió asimismo la tarea de ampliar el programa que la entidad tenía para difundir el conocimiento científico. Este programa era vital pues, una vez más, la institución tenía dificultades económicas y Faraday consideraba una cuestión de deber y gratitud ayudarla en la solución de esta difícil situación y contribuir a su firme consolidación. Entre 1826 y 1827 inició dos aventuras educacionales exitosas para el entendimiento público y la popularización de la ciencia: las charlas vespertinas de los Viernes, dirigidas a un auditorio conformado en gran proporción por personas sin mayor educación en ciencia, y las conferencias juveniles de Mavidad, especialmente dedicadas a los niños, actividades ambas que aún continúan desarrollándose en la Royal Institution. El propósito esencial, tanto de las charlas como de las conferencias, era divulgar el conocimiento científico (en un alto porcentaje el correspondiente al logrado con base en los trabajos desarrollados en las instalaciones de la Institución) a un nivel accesible al público en general. Faraday era de la creencia que este tipo de lecturas debería "divertir y entretener, tanto como educar, edificar, y ante todo, inspirar". El programa ampliado de conferencias atrajo nuevos miembros y aseguró la continuación del apoyo de los que ya lo eran. Sus suscripciones contribuyeron a rescatar a la Royal Institution de sus dificultades financieras, y a incrementar su visibilidad al exterior de sus instalaciones. Faraday no sólo se encargó personalmente de la organización de las charlas de los Viernes hasta 1840, sino que fue uno de los principales conferencistas en las mismas, y en aquellas de Mavidad hasta los primeros años de la década de 1860. Las últimas conferencias suyas atrajeron auditorios de más de 800 personas, y si bien sus honorarios se habían incrementado por lo que percibía por ellas (generalmente unas 100 libras por un ciclo completo), la motivación esencial para su ofrecimiento radicaba en la profunda convicción que tenía respecto a que el conocimiento no era algo que debía mantenerse guardado en los laboratorios de un sótano y transmitirse sólo a otros hombres de ciencia, sino que debía ser comunicado a un auditorio más general. Su éxito como divulgador se destaca aún en la actualidad con el establecimiento por parte de la Royal Society, desde hace algo más de una década, del "Premio Faraday", el cual es concedido, previa recomendación de un Comité establecido para ello, a los científicos que contribuyan significativamente a la compresión pública de la ciencia. Una descripción más detallada de ésta, una de las facetas más elogiadas de su reconocida actividad científica, no sólo constituiría una estimulante lectura por lo que ella significó en su época, y las implicaciones que ha tenido hasta la fecha, sino que se hace necesaria al observar el paulatino aislamiento de la comunidad científica del público en general, debido, principalmente, al establecimiento de la ciencia como una actividad cada vez más especializada y profesionalizada, en donde la separación entre la investigación y la enseñanza es todos los días más evidente. La extensión del presente artículo no permite, sin embargo, entrar en más detalles al respecto.

\section{La Madurez del Trabajo Científico:}

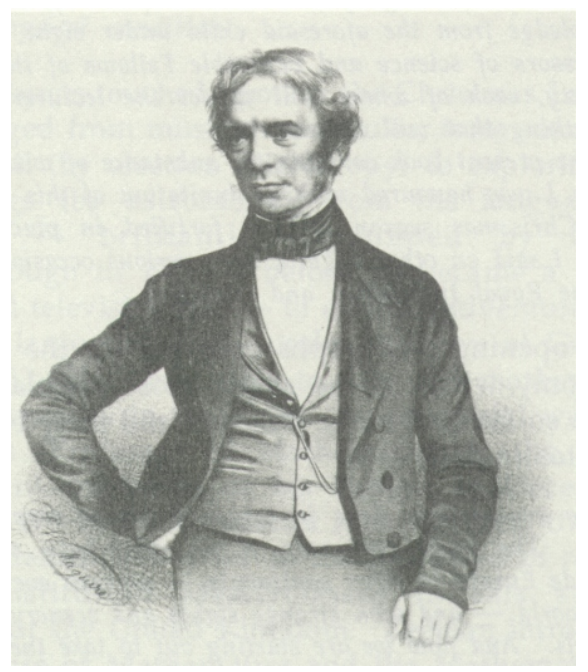

Michael Faraday 
A comienzos de la década de 1830 Faraday estaba dedicado más a sus trabajos en química que a sus experimentos electromagnéticos, aunque las ideas alrededor de estos últimos no se apartaban de su mente. Unos años antes había descubierto algunos compuestos orgánicos, entre los cuales debe mencionarse uno que llamó inicialmente "bicarburato de hidrógeno", y que en la actualidad es conocido como benceno. En 1827 declinó una invitación a convertirse en el primer profesor de Química en "University College", en Londres, pero dos años después fue nombrado igualmente Profesor de Química en la "Royal Military Academy", en Woolwich. Su trabajo consistía en ofrecer un promedio de veinticinco conferencias al año, por lo que recibiría un sueldo adicional de 200 libras en ese mismo período. La vinculación se extendió por espacio de veinte años. Las condiciones de su contratación, tanto económicas como de facilidades (sólo tenía que permanecer dos días a la semana en Woolwich, lo que le permitiría compaginar su nuevo trabajo con las actividades normales en la Royal Institution) comparadas con las de otros profesores en el área humanística, por ejemplo, en la misma Academia, refleja la creencia que por esa época tenían las fuerzas militares (tanto la armada como la naval) del definitivo papel a desempeñar por la ciencia en el futuro de las mismas, y que por ello resultaba sin sentido emplear, o continuar empleando, en esas áreas, personas de segundo nivel. Este mismo criterio no era compartido aún, decididamente, por otras esferas del gobierno. Actividades como las de Faraday, en electricidad y magnetismo, o las de cualquier otro científico contemporáneo, nunca serían apoyadas financieramente por parte del gobierno a menos que tuvieran una tendencia utilitarista. En otras palabras, la tendencia imperante era que sólo recibían apoyo estatal aquellos trabajos de breve duración en el tiempo, con objetivos precisos y propósitos de aplicación práctica seguros de lograr.
En los años en que Faraday inició su carrera la actitud de los hombres de ciencia, en su gran mayoría, era que la escogencia de los temas de sus investigaciones no debía ser influenciada por este tipo de criterios. La investigación por si misma era entonces competencia exclusiva de cada individuo. Si alguien quería llevarla a cabo, tenía que sacar tiempo de sus otras actividades y utilizar recursos propios. Esta manera oficial de apreciar el trabajo científico comenzó a cambiar, sin embargo, durante el transcurso de la vida de Faraday, debido, en parte, sin lugar a dudas, a los efectos de sus contribuciones. Faraday era consciente de esta situación, y sabía que sólo era posible disponer de financiación estatal o de cualquier otro tipo para adelantar actividades científicas si habían argumentos sólidos que permitieran creer en que podría derivarse algún beneficio material de ellas. Sin embargo, para él la aplicación potencial de la ciencia no era la única, ni aún la principal razón para trabajar en ellas. Él tenía muy en claro ésto desde el inicio de su carrera, y se refirió a ello en una de sus primeras conferencias, ofrecida ante la City Philosophical Society. En ella, Faraday citó un aforismo famoso de Benjamín Franklin: "qué útil es un bebe recién nacido?". Franklin había utilizado esa frase en 1783 al hablar sobre un logro científico para el cual no había una utilidad obvia; Faraday la usó para hacer referencia al caso específico del cloro. Descubierto en 1774 por Carl Wilhelm Scheele, el cloro no tenía en ese momento, aparentemente, ninguna utilidad; sin embargo en 1816 ya se trataba de un compuesto químico importante, utilizado en particular en el blanqueo de la ropa. Lo que él quería dar a entender, en pocas palabras, es que no se puede saber con anticipación cuáles serán las aplicaciones tecnológicas del conocimiento científico. Su pensamiento no varió con la experiencia y la reputación como hombre de ciencia alcanzados durante su productiva vida. La principal razón para hacer ciencia, según él, era la obligación moral de entender el mundo que Dios había creado. Por supuesto, Dios podía para 
ello tener en cuenta también el desarrollo de nuevas tecnologías a partir de descubrimientos científicos. Faraday hizo explícito este punto durante una conferencia sobre el telégrafo eléctrico. En sus propias palabras concluyó que "al permitirle a la mente aplicar la energía natural a través de la ley, se transfieren los dones de Dios al hombre". En este caso la mente del hombre había sido capaz de utilizar la energía natural de la electricidad para el objetivo de la telegrafía. De esta manera exponía un ya ampliamente difundido y sostenible punto de vista de la ciencia y la tecnología, aunque quizás con un matiz más teológico del que muchos de sus contemporáneos le habrían dado.

Faraday adicionalmente creía que la aplicación específica explícita de la ciencia a la tecnología (como en el caso de su trabajo en el mejoramiento del vidrio para usos ópticos) no garantizaba necesariamente la obtención de resultados útiles, y más aún, su propia experiencia podía indicarle que era muy probable que ocurriese todo lo contrario. Por esta razón, en su conferencia de 1858, tuvo mucho cuidado de mantenerse distanciado del punto de vista que establecía que la educación científica debería responder a propósitos vocacionales. Él, más que nadie, sabía que la investigación en ciencia no podía dirigirse hacia el cumplimiento de un objetivo tecnológico preestablecido, sino que debía guiarse por la imaginación y creencias del investigador; si se presentaban consecuencias útiles a nivel tecnológico mucho mejor. El caso de la electricidad, argumentaba, justificaba plenamente su posición de que los hombres de ciencia deberían ser libres de dedicarse a desarrollar sus propias ideas, independientemente de las aparentes necesidades de ciertos grupos dentro de la sociedad. De esta manera, hábilmente hizo uso del ejemplo del telégrafo para mostrar como el aparentemente inútil fenómeno de la electricidad podía ser la base de una gran industria.

\section{Un Brillante Descubrimiento y una Teoría Excepcional:}

En 1831 Faraday ya había alcanzado tranquilidad económica y disponía del tiempo necesario para llevar a cabo sus propias investigaciones. Estos factores y el mismo hecho de que la situación financiera de la Royal Institution había mejorado notablemente (aspecto que habría de permanecer así durante el resto de su carrera), le permitieron la posibilidad de darse el lujo de no aceptar embarcarse en proyectos que no eran de su interés. Aprovechó esa libertad para dedicarse a una serie de investigaciones que en últimas transformarían el entendimiento del mundo físico. De manera súbita suspendió temporalmente sus trabajos en química, y se dedicó de lleno al problema que abarcaba toda su mente, y que había permanecido de manera casi que incontrolable en ella desde que hizo el descubrimiento de las rotaciones electromagnéticas: ¿si una corriente eléctrica podía producir magnetismo, un imán no sería capaz de producir electricidad?. Algunos experimentos preliminares en esa dirección, en los que había tratado de inducir corriente en un alambre al colocar éste en las proximidades de un imán, habían fracasado. Él no era consciente aún de la importancia central del movimiento en el fenómeno que Oersted había demostrado. Era el movimiento de la corriente eléctrica en el alambre lo que producía magnetismo. Si ésto era así, no sería posible obtener el efecto opuesto al mover el imán en relación con el conductor?

En agosto 29 de 1831 Faraday, utilizando un dispositivo de gran simplicidad, lleva a cabo exitosamente una serie de experimentos, logrando el efecto que tanto había buscado: había descubierto la inducción electromagnética, el principio en el que se fundamenta el funcionamiento del transformador eléctrico y el dinamo. Una serie de experimentos similares continuaron hasta Moviembre de ese año, con 
unas pocas variaciones respecto al trabajo inicial. De esta manera él es el responsable de haber colocado los "cimientos" de la actual industria eléctrica. Reportó enseguida sus resultados a la Royal Society, cuya publicación posterior fue el inicio de una larga serie de memorias relacionadas, que bajo el título "Experimental Researches in Electricity" se completó después de veinticinco años. Estas memorias, publicadas en tres volúmenes, han sido comparadas a nivel de su importancia histórica con los "Principia" de Mewton y "El origen de las especies" de Darwin. La divulgación de su trabajo le permitió rápidamente seguir solidificando su reputación como científico de alto nivel. Era ahora un investigador lleno de confianza en sí mismo, capaz de desarrollar un extenso programa de trabajo, combinando de manera creativa especulaciones, inferencias y una incisiva experimentación.

El lector no se extrañará si hacemos referencia en este punto a un hecho de cierta manera recurrente en la obra de Faraday. Tan pronto aparecieron publicados los resultados, el asunto de la primacía saltó de nuevo a la palestra. De un lado el físico americano Joseph Henry afirmaba ser el verdadero descubridor de la autoinducción, y por el otro los italianos Leopoldo Mobili y Cavaliere Antinory reclamaban el crédito por el descubrimiento de la inducción electromagnética aún antes de la publicación inicial de las memorias del científico inglés. Posteriormente se ha verificado que los experimentos realizados por ellos indican de manera casi inequívoca un previo conocimiento de su parte del método seguido por Faraday y los resultados originales por él obtenidos, eliminando así cualquier manto de duda que pudiese existir sobre la prioridad en el descubrimiento. Historiadores más recientes han reasumido el tema con base en unos elementos nuevos, los cuales podrían dar lugar a la presencia de pequeñas inexactitudes en la historia.
Faraday, sin embargo, no estaba satisfecho con haber descubierto la inducción electromagnética; él quería saber por qué ocurría. Trabajando en este campo, comenzó a formular hipótesis sobre el mecanismo del fenómeno. Resulta demasiado complicado y extenso detallar aquí la ruta completa por la que arrivó a una explicación científica que lo dejó satisfecho. Mo obstante, es importante situar al lector en el tiempo de esta descripción, y mencionar el estado momentáneo de algunas teorías aceptadas y otras en discusión por esa época. Los fenómenos de atracción y repulsión eléctrica y magnética (tal como ya se mencionó en una breve alusión anterior) ya se encontraban en las carpetas de los hombres de ciencia desde hace varias décadas, debido a su innegable suceso. El mismo siglo XVIII resultó ser un período de gran actividad en la investigación de la electricidad y el magnetismo, pero las por ese entonces aún tempraneras explicaciones para esos fenómenos no eran satisfactorias. La posibilidad de que tanto el uno como el otro no fueran sino diferentes modos de acción de las subyacentes y fundamentales fuerzas de atracción y repulsión era un dogma o principio primario de la filosofía dinámica Kantiana. Uno de los más fervientes discípulos de Kant, el danés Oersted, había dedicado veinte años de su vida a hacer manifiesta esta posibilidad. Habían, por la época de Faraday, algunas teorías, aparentemente ya establecidas, que deberían ayudarle a encontrar la explicación que buscaba: una de ellas era la debida al trabajo del físico francés Charles August Coulomb. Esa teoría, sin embargo, presentaba algunos aspectos implícitos, que por la "intuición" de Faraday- por llamarla de alguna manera- no le permitía aceptarla. Coulomb, en unos trabajos realizados en 1775, había deducido definitivamente, con base en experimentos, una ley (antes trabajada de manera separada por Aepinus, Priestley, Robinson y Cavendish) por la cual se establecía que la fuerza existente entre dos cargas eléctricas debía ser función del producto de las 
magnitudes de dichas cargas, e inversamente proporcional al cuadrado de la distancia entre ellas. El científico francés argumentaba que de esa manera trabajaban las fuerzas gravitacionales, y que si en ellas se daba la acción a distancia, en cualesquier otras también debía darse. Con base en este desarrollo, Dennis Poisson construyó posteriormente una hermosa teoría matemática correspondiente, estableciendo el concepto de potencial eléctrico.

Las inquietudes de Faraday estaban ligadas a aspectos concretos que, a su juicio, no habían sido aún debidamente estudiados y menos claramente establecidos: la naturaleza de la electricidad, la del magnetismo, la conexión entre éstas, su relación con la materia en sí misma, y el papel a jugar en estas relaciones por un elemento fundamental como es el espacio. Él tenía muy claro que éstos, además de otros factores, debían ser sujeto de estudio y experimentación, previos a la formulación de nuevos desarrollos. Entrar a analizar aquí detalladamente cada uno de estos elementos sería prohibitivamente largo, pero sí pueden hacerse algunos comentarios que permitan visualizar mejor la historia.

¿Qué ideas habían implícitas en la teoría de Coulomb, y cómo se comparaban con los resultados de los experimentos de Faraday?. Ahí estaba la clave. Coulomb siempre había sostenido la idea de que la interacción entre electricidad y magnetismo era imposible, dado que se trataba de "fluidos" esencialmente diferentes, y que cada uno actuaba sobre sus "iguales". Faraday, como ya lo vimos, había demostrado varias décadas después de él que esta interacción no sólo era posible, sino evidente. El segundo aspecto era uno que por mucho tiempo estuvo presente en su mente: ¿"Será que la electricidad tiene una existencia real e independiente en la forma de un o unos fluidos, o más bien que se trata de una simple fuerza o energía de la materia, tal y como la concebimos en el caso de la atracción gravitacional"?. El asunto era el punto decisivo de la diferencia entre su teoría de la acción eléctrica y aquella sostenida por la gran mayoría de sus contemporáneos. Todas las teorías clásicas de la época -las de Coulomb, Poisson, Ampère- suponían que el fenómeno eléctrico podía entenderse al asumir "fluidos" separables de la materia, dotados de ciertas energías. Faraday, prácticamente de manera solitaria, creía que la energía eléctrica estaba intrínsecamente relacionada con la materia en sí misma. De acuerdo con las otras teorías, "los dos fluidos de la electricidad" (lo que hoy asociamos con los conceptos de atracción y repulsión) deberían ser capaces de "separarse" y susceptibles de ser estudiados por sí mismos. De acuerdo con Faraday, "las dos electricidades" eran simplemente manifestaciones diferentes de una misma clase de energía de la materia, y no podían separarse de ella más que por la afinidad química o la gravedad.

Ante todo este razonamiento era obvio que él no podía adherirse a explicaciones tan imperfectas e incompletas como las ya mencionadas. Había, sin embargo, un aspecto más, para dar, de cierta manera, el puntillazo que esas teorías requerían: el espacio. Faraday no concebía que el espacio "vacío" que separaba dos objetos no desempeñara un papel más importante en el mecanismo que gobernaba las fuerzas entre ellos que el mero hecho de proveer esa distancia. Ésta era una dificultad que podríamos denominar metafísica. A diferencia de la mayoría de sus contemporáneos, los cuales definían el espacio en términos geométricos (es decir como el lugar en donde pueden ocurrir procesos físicos), Faraday lo hacía en términos físicos (es decir como algo que además podía participar en la realización de dichos procesos). Su teoría exigía que el espacio participara; las propiedades de éste debían incidir de alguna manera en la realización del fenómeno $y$, por ende, formar parte de la explicación del mismo. Fruto de todo 
este arduo y coherente razonamiento fue surgiendo en su mente la explicación deseada al fenómeno de la inducción electromagnética, proceso al que dedicó muchos años de trabajo y análisis. Incapaz de aproximarse al tema matemáticamente, recurrió a un modelo físico: el concepto de campo en los espacios que rodean tanto el imán como el alambre conductor de corriente eléctrica, al cual Maxwell se referiría posteriormente como "la trama de un tejido urdido en el firmamento". Haciendo uso de un procedimiento experimental didáctico de mucha popularidad hoy en día en los laboratorios de física a nivel secundario y universitario (e incluso de implementación casera), y cuyos resultados gráficos son ilustrados en textos clásicos del tema, por el cual, con la ayuda de una pequeña cantidad de hierro en polvo esparcida sobre una delgada hoja de papel, debajo de la cual está colocado un imán en barra, se revelan unos trazos luego de unas suaves sacudidas, Faraday demostró la existencia de lo que denominó como "líneas de fuerza", las cuales claramente formaban un patrón ordenado alrededor del magneto. El propuso la idea de que el espacio que rodeaba el imán estaba lleno de líneas de fuerza. La fuerza magnética se manifestaba entonces como líneas invisibles en estado de tensión (similar a bandas de caucho estiradas) y las limaduras de hierro se ordenaban por sí mismas debido a la atracción magnética a lo largo de dichas líneas.

Faraday no paró allí. Llenó todo el espacio con líneas de fuerza, y esquematizó el concepto revolucionario de que éste estaba saturado de diversas clases de fuerza: magnética, eléctrica, radiante, térmica y gravitacional. Las líneas indican en cualquier punto la duración y la intensidad de la fuerza bajo consideración. Por ejemplo, en una barra de imán la dirección de las líneas de fuerza es de positivo a negativo, o del polo norte al sur, y el número de ellas, provenientes de un polo magnético, indican su intensidad en un lugar dado. Ellas son más densas en las proximidades del magneto, con respecto a aquellas localizadas a una mayor distancia de éste en el espacio. De manera similar, la cantidad de electricidad que un cuerpo posee se determina, de acuerdo con Faraday, por el número de líneas de fuerza provenientes de él. Todas las líneas de fuerza terminan en algún lugar: ya sea sobre otro cuerpo próximo, sobre los muros de un cuarto, o sobre los planetas en el espacio. Cualesquiera sea el punto donde terminen, allí hay una cantidad de electricidad igual en magnitud, pero con carga opuesta, a la del cuerpo original. Faraday razonó que la teoría de las líneas de fuerza explicaba el porqué una corriente se induce en un conductor: ello ocurre cuando el conductor "corta" o "atraviesa" las líneas magnéticas de fuerza. Así mismo descubrió que la velocidad del movimiento era importante: "si un alambre se mueve lentamente", escribió, "se produce en él una débil corriente, continuando así durante el tiempo del movimiento; si éste se mueve más rápidamente a través de las mismas líneas, una corriente más fuerte se producirá por un tiempo más breve". Estrictamente hablando, lo que se induce no es la corriente sino un voltaje (la primera resulta simplemente como consecuencia de la segunda).

Lo revolucionario en el concepto de campo radica exactamente en eso: el nuevo elemento que introdujo en el estudio de la Física. Antes de Faraday todos los físicos y sus teorías se concentraban en la partícula material. Del concepto de partícula ellos intentaban derivar y explicar todos los fenómenos. Los procesos físicos se explicaban en virtud de las leyes del movimiento Mewtoniano y las fuerzas de interacción mutua que actuaban sobre la partícula. Faraday relegó (no reemplazó) el concepto de partícula a un segundo plano, y colocó en primer término el de las líneas de fuerza en todo el espacio. Para él lo más importante no eran las partículas eléctricas o magnéticas, sino el 
espacio en que ellas operaban. Esta era la base completa del concepto de campo, y lo fundamental de la teoría radica en las condiciones físicas y geométricas del espacio en sí mismo. De cierta manera puede decirse que su teoría es dual: tanto la partícula como el campo son fundamentales, pero es este último el que juega el papel más preponderante.

Introducidas inicialmente como un auxilio de memoria y utilizadas después como un concepto descriptivo no sólo para el caso de la inducción electromagnética sino para otra gran variedad de fenómenos, las lineas de Faraday se convirtieron en una poderosa herramienta teórica que posteriormente William Thomson y James Clerk Maxwell, entre otros, encontraron particularmente útil. Sin necesidad de hacer ninguna referencia adicional a otra(s) de sus contribuciones, ésta sola, por sí misma, coloca a Faraday como uno de los precursores de la moderna revolución relativista en física, y su construcción del concepto de campo debe considerarse como una de las más grandes creaciones de la mente científica.

\section{El Trabajo Científico no se Detiene:}

Posterior a su descubrimiento de la inducción electromagnética se presentaron una serie continua de trabajos que implicaron igualmente grandes aportes. Desvirtuó definitivamente la errada, pero hasta ese entonces vigente, teoría (a la que hicimos alusión en la sección anterior) de que la electricidad era una especie de fluidos recorriendo un alambre , $y$ en su lugar empezó a crear la cultura de referirse a ella como una especie de acción que tomaba lugar entre las partículas de dicho alambre, y desarrolló otros experimentos en electromagnetismo. En 1833 fue honrado con el nombramiento de Profesor Fulleriano de Química, un puesto creado especialmente para él, con un salario de 100 libras al año. Esto se sucedió durante un período en el que estuvo particularmente ocupado. Entre Enero de 1832 y Diciembre de 1834 publicó aproximadamente veinte artículos originales, desarrolló diecisiete conferencias vespertinas de los Viernes, ofreció seis charlas juveniles de Mavidad sobre química, además de cuarenta y ocho presentaciones de diferente nivel sobre diversos tópicos en Física y Química, todas ellas en la Royal Institution. Así mismo llevó a cabo una serie de 75 conferencias en la Academia Militar en Woolwich y estableció una extensa relación de correspondencia con numerosos personajes de la época, entre los que pueden mencionarse a Ampère, Charles Babbage (uno de los pioneros del actual computador) Berzelius (uno de los más importantes químicos de la época), Mary Sommerville (la matemática y divulgadora científica), William Whewell (Profesor del Trinity College en Cambridge), Gay-Lussac, etc. En ese mismo período continuó con los trabajos de asesoría, actividad a la que había dedicado tiempo desde el inicio de su carrera. Esta época se caracterizó, entre muchas cosas, por el papel cada vez más importante que los científicos fueron desempeñando en la vida civil, aplicando sus conocimientos a temas tales como la seguridad en los ferrocarriles, la salud pública y la limitación de las emisiones gaseosas de las chimeneas de las fábricas. El científico jugaba un papel cada vez más importante en la consolidación de las instituciones del Gobierno Central y como colaborador de las mismas, en su calidad de experto. Faraday, como parte de ese movimiento, recibía solicitudes de asesoría de instituciones como el Almirantazgo, el Ministerio del Interior y diversas comisiones reales, en cuestiones que afectaban a la sociedad y para las que aún no se disponía de legislación. Así, por ejemplo, colaboró con entidades que se ocupaban de cuestiones como el alumbrado con gas de las galerías de arte, la sede de la Mational Gallery, el mantenimiento de las luces de los puertos o el estado del alcantarillado en la ciudad. 


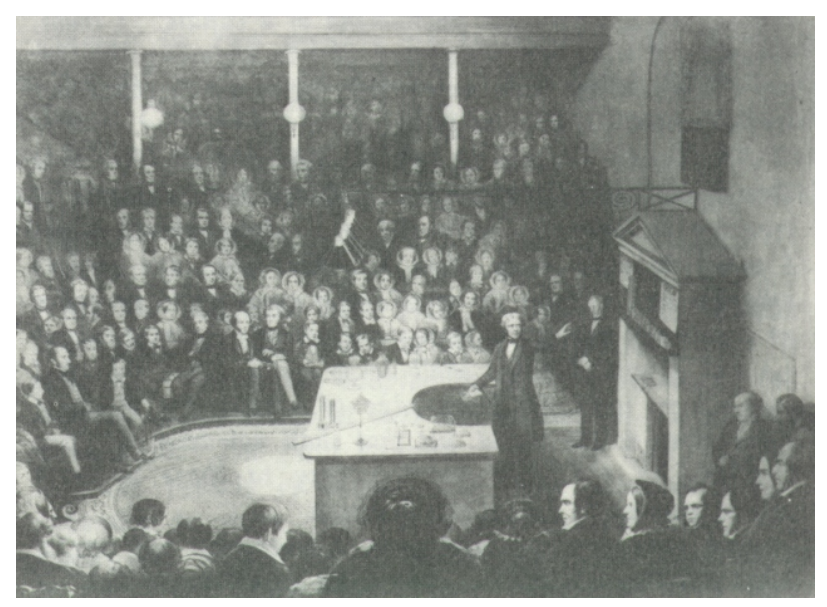

Faraday llevando a cabo una de sus Conferencias de Mavidad.

1855

Sin lugar a dudas, el trabajo más significativo en ese período específico fue el establecimiento de las denominadas leyes de la Electroquímica, a las que llegó al intentar averiguar cómo se relacionaba la electricidad con la materia, y para ser más preciso, con las propiedades químicas de ésta. La Electroquímica, o como Faraday la llamó electrólisis- puede considerarse como el "hijo menor" en la generación de diversas ramas de la electricidad a comienzos del siglo XIX. Tuvo sus preliminares con la invención de la pila o batería por parte de Volta (en los primeros meses de 1800), pero su "bautizo" formal se atribuye a Micholson y Carlisle, alrededor de la misma época, cuando utilizando una clase de baterías idénticas a la diseñada por el físico italiano, llevaron a cabo por primera vez la electrólisis del agua, es decir la producción de hidrógeno y oxígeno gaseosos a partir de ésta, utilizando para ello exclusivamente la electricidad generada en el equipo en cuestión. El trabajo de estos hombres inspiró a otros en el continente, entre ellos a Davy (quien hizo uso de la nueva técnica para aislar algunos elementos) y de paso a Faraday.

Hasta la década de 1830 todos los investigadores en electrólisis habían asumido que los alambres conectados a la pila voltaica e insertados en una solución -polos, como generalmente se les llamaba- ejercían una "acción a distancia" siguiendo la ya mencionada ley de Coulomb del cuadrado inverso, que el autor había demostrado aplicaba a cuerpos cargados con electricidad estática. Faraday, quien inició sus estudios en esta área en 1833, concluyó todo lo contrario al hacer una serie diversa de experimentos utilizando diferentes formas de producir la electricidad, tales como generadores electrostáticos, celdas voltaicas e incluso descargas del denominado pez (torpedo) eléctrico. Esta serie de experimentos le sirvieron fundamentalmente para dos propósitos. El primero, para confirmar efectivamente que las reacciones electroquímicas no se sucedían por "acción a distancia", ya que de ser así la cantidad de material depositado o producido habría dependido tanto del potencial eléctrico como del tamaño de la vasija utilizada, cosa que no indicaban sus resultados. Lo segundo, fue que le permitieron demostrar lo que él denominaba "identidad de electricidades" . En efecto, para esa época era normal referirse a cada una de ellas según su respectiva fuente: la estática, producida por fricción, se llamaba friccional o (debido a su familiaridad) electricidad "común"; la corriente, producida por una pila química era la "electricidad voltaica", y ya que el descubrimiento de Volta tenía su origen en la controversia con los experimentos de Galvani relacionados con las convulsiones de las patas de las ranas, en ocasiones también se les denominaba "galvanismo" o "electricidad animal"; el calentamiento desigual de dos metales producía "termo-electricidad"; y las corrientes magnéticamente inducidas, que él mismo había descubierto, se llamaban, obviamente, "magneto-electricidad". Gracias a su trabajo experimental pudo comprobar que su hipótesis, en el sentido de que todas estas electricidades eran formas diferentes de un único poder, era cierta, y de paso cumplir con su deber de conectar cada uno de los aspectos de la creación 
y poner de manifiesto la unidad del plan de Dios.

Sin embargo, la principal contribución de faraday fue, como ya dijimos, el planteamiento de las leyes de la Electroquímica, además de la creación de un nuevo vocabulario para esta rama de la ciencia. En 1834 enunció dos leyes que se sitúan entre las más precisas generalizaciones de la ciencia, las cuales, en pocas palabras, describen en términos cuantitativos la relación existente entre el grado de descomposición química de una sustancia conductora y la cantidad de electricidad que pasa a través de ella. En cuanto a lo del vocabulario, él es responsable, en conjunto con William Whewell, de la introducción de nuevos términos como ión, anión, catión, electrodo, cátodo, ánodo y electrolito, los cuales hoy en día son universalmente aceptados.

En los años que siguieron, se dedicó a temas diversos como la autoinducción y la inducción mutua, la inducción electrostática, su distinción entre conductores y aislantes, el nuevo material que denominó "dieléctrico", la capacidad inductiva específica, etc., temas estos de igual importancia a los ya referenciados, pero que por las ya reiteradas y obvias razones de espacio y organización, sólo se mencionan en el presente artículo.

\section{Una Pausa Obligada... y de nuevo en la Ciencia:}

La gran cantidad de resultados que obtuvo Faraday en sus investigaciones en las décadas de 1820 y 1830 contrastan con los primeros años de la de 1840, en los cuales su actividad investigadora prácticamente se interrumpió. Así mismo, sus conferencias en la Royal Institution fueron menos frecuentes. Los motivos para este cambio fueron fundamentalmente sus problemas de salud. Aunque ya anteriormente se había quejado de algunas dolencias, el problema de ese momento era de agotamiento extremo, vértigo, dolores de cabeza y principalmente pérdida de memoria. Algunas conjeturas al respecto indican que una posible razón para este cuadro podría haber sido el envenenamiento con un metal pesado como el plomo, el mercurio u otras sustancias químicas tóxicas que utilizaba en grandes cantidades para la realización de sus experimentos. Otra hipótesis plantea que el "colapso" de estos años pudo haber sido motivado por tensiones psicológicas sin resolver, las cuales están frecuentemente asociadas con personalidades obsesivas. De cualquier manera, la causa real de sus problemas no ha sido identificada con precisión.

A mediados de la misma década Faraday estaba de nuevo dedicado en pleno a sus investigaciones y a su tarea de conferencista. En estos años perfeccionó su idea de campo y la teoría de las líneas de fuerza a la cual hicimos referencia previamente. Sus principales descubrimientos en esta etapa fueron el denominado "efecto Faraday", es decir la rotación del plano de polarización de la luz por efecto de un campo magnético, lo que se constituyó en la primera relación verificable entre luz y magnetismo, y una nueva clasificación de sustancias con base en su identidad magnética, es decir de acuerdo con la posición que tomaran respecto a las líneas de fuerza en un campo magnético: transversal o axial; las primeras las denominó "diamagnéticas", para diferenciarlas de las otras que son imanes comunes. Así, por ejemplo, una pieza de vidrio pesado, que él colocó entre los polos de un poderoso electroimán, mostró una clara tendencia a situarse por sí misma perpendicular al campo magnético en el plano horizontal. El experimento no hubiera tenido nada de destacado si no se supiera que el material utilizado era uno tradicionalmente reconocido como nomagnético; se trataba de vidrio, no de ningún imán. Estimulado por sus resultados, Faraday repitió el experimento con una gran variedad de materiales: sales minerales, 
vegetales, tejidos animales, etc. La conclusión era inequívoca: todas las sustancias son magnéticas en cierto grado, aunque en la mayoría de los casos dichos efectos son apenas perceptibles.

El recuento de estos experimentos ha despistado sin embargo a generaciones de estudiantes, ya que se bien es cierto es posible la presencia de magnetización en un cuerpo al observar la fuerza sobre él en un campo magnético, ésto sólo puede ocurrir cuando éste no es uniforme, ya que como se sabe ninguna substancia magnética experimenta una fuerza neta en un campo magnético uniforme, independientemente de la forma o el material del cual esté elaborada dicha substancia. Afortunadamente es más fácil disponer de un campo magnético no uniforme que de uno que sí lo es, lo cual permite establecer la distinción. Algunos textos se refieren a que Faraday fue capaz de distinguir no dos, sino tres clases de materiales: aquellos que al ser colocados en un campo como el ya descrito experimentan una ligera atracción hacia la región donde éste es más fuerte (paramagnéticos); otros que hacen justamente lo opuesto, lo que en otras palabras indica que su magnetización inducida es opuesta a aquella del propio campo (diamagnéticos), y la tercera clase que incluye el hierro, sodio y algunas de sus aleaciones (ferromagnéticas). Mo importa cuál sea el número de clasificaciones posibles; el hecho es que él de cierta manera estableció un "código" magnético para las sustancias, y de esta manera puede decirse que dio el mayor paso para el establecimiento de la moderna y aún incipiente disciplina de la "magnetoquímica", el estudio sistemático de las propiedades magnéticas de los materiales.

En 1858 Faraday y su esposa abandonaron su vivienda en el piso superior de la Royal Institution y pasaron a ocupar una casa que les habían cedido en Hampton Court. Continuó ofreciendo las charlas de los Viernes hasta los primeros años de la década de 1860. En 1862 llevó a cabo su último experimento, relacionado nuevamente con la conexión entre luz y magnétismo. Su propósito, que no logró, era percibir cualquier cambio en la posición precisa de las lineas del espectro de una llama sobre la que actuaba un poderoso imán. Resulta apenas obvio que no hubiera observado ningún efecto, dado que la calidad de los espectroscopios de la época, basados como lo estaban en prismas, era bastante deficiente. Reafirmado en su fe cristiana y en la esperanza de la vida eterna, Faraday dejó de existir el 25 de agosto de 1867. La humanidad, sin embargo, continuará disfrutando sin límite de los beneficios de su ingenio y creatividad.

\section{Aclaraciones y Comentarios:}

El presente artículo ha tenido como propósito esencial ofrecer una breve biografía de Michael Faraday. Mo obstante la evidente extensión del mismo, el término "breve" no debe interpretarse como irónico. Tratar de escribir en poco espacio la biografía de un hombre de ciencia no es labor fácil, y menos aún si se trata de una figura multifacética como el personaje en cuestión. El objetivo central ha sido presentar los aspectos más destacados de su vida, reservando para artículos posteriores el análisis particular de algunas de sus facetas más relevantes. Sin embargo, y como ya se mencionó en el texto, resultó ineludible y necesario hacer algunas referencias a su obra, para situar la historia en un contexto apropiado. Si bien se trató de presentar el tema de la manera más cronológica posible, las características propias del trabajo obligaron, de cierta manera, a realizar pequeños saltos en una y otra dirección con el propósito de darle mejor hilación a la exposición. Por otro lado, debe aclararse que el mayor énfasis dado en algunos apartes del presente material, no es necesariamente dictaminado por la creencia de 
una evidente mayor importancia de los mismos respecto al resto del tema, y obedece, parcialmente, a consideraciones y gustos propios del autor.

El autor agradece por anticipado todos los comentarios, sugerencias y críticas constructivas en general que sobre el texto u omisiones dentro del mismo deseen hacerle los lectores de la revista, lo que redundará en un deseado incremento de sus conocimientos en el tema. Espera, en ese mismo orden de ideas, haber sido capaz de motivar en algún grado la continua lectura de materiales sobre la vida y obra de un hombre que, prácticamente, se ha convertido en leyenda científica. Mo de otra manera se explica que, hasta la fecha, se hayan publicado por lo menos cuarenta y un biografías suyas diferentes (sin contar otras dos actualmente en preparación), además de un número mucho mayor de artículos específicos en revistas especializadas.

Faraday no fue un hombre común en su tiempo, y menos lo sería si pudiésemos transportarlo a la época actual. O cree el lector que resultaría fácil encontrar un ser humano que reúna si no todas, al menos algunas de las siguientes características, para citar sólo las más reconocidas, además de las ya explícitas o implícitas en el cuerpo central del presente artículo?: Alguien que incursionara en por lo menos diez áreas de la química y en un número no menos apreciable de campos en otras ciencias físicas, y en todas ellas de manera exitosa?; alguien cuya práctica de la ciencia-en donde la física y la química constituían su gran pasión- estaba exclusivamente impulsada por el deseo de comprender la materia, las fuerzas y las leyes que Dios había producido en la creación?; alguien que, pudiendo haber hecho una fortuna con sus descubrimientos, simplemente los abandonaba de manera deliberada cuando algún proyecto científico en el que trabajaba alcanzaba la etapa de explotación comercial, dado que para él la adquisición del conocimiento era suficiente recompensa?. Sin lugar a dudas, encontrar una persona así, quien combinaba, además de las características ya mencionadas, un par de cualidades adicionales notables como son una energía intelectual casi inagotable, y una honestidad a toda prueba, es en cualquier época una labor muy difícil. A ello debe agregarse su profundo convencimiento de que para todos los problemas que enfrentaba debía haber siempre una solución lógica y científica, y que para todas las preguntas que se hacía existían respuestas apropiadas. Poseía además el muy escaso don de saber seleccionar apropiadamente aquellos interrogantes que para el análisis de una situación específica eran realmente importantes, e identificar con precisión cuál era el próximo a resolver. Todo ello, su prodigiosa vitalidad, una curiosidad sin límites, capacidad de autocrítica, autodisciplina, intuición penetrante, y una excepcional facilidad para pasar de lo particular a lo general, hacen de Faraday una figura científica casi sin paralelo en la historia. Para terminar, hablando de él, se puede hacer referencia a una frase originalmente dedicada a Shakespeare en alguna oportunidad, pero que igualmente representa de manera perfecta su figura: "Él no fue de una época, sino para todos los tiempos".

\section{Bibliografía:}

BERKSOM, W.; " Las teorías de los campos de fuerza", Alianza Editorial, Madrid (1981).

BROCK, W.H.; "The Chemical Tree: A history of Chemistry", W.W. Morton \& Company, Mew York (1993).

CAMTOR, G.; "Michael Faraday: Sandemanian and Scientist", MacMillan Academic and Profesional Ltda., Londres (1991). 
CARDWELL, D.; "Historia de la tecnología", Alianza Editorial, Madrid (1994).

FEYMMAM, R.; "El carácter de la ley física", Ediciones Orbis, S.A., Barcelona (1986)

GAMOW, G.; "Biografía de la física", Salvat Editores, Madrid (1971)

GOODIMG, D. Y JAMES, F.A.J.L. (eds.); "Faraday rediscovered", The MacMillan Press Ltda, Londres (1989).

HEILBROM, J.L.; "Electricity in the 17th and 18th centuries: A history in early modern physics", Dover Publications Inc., Mew York (1999).

LEE, E. W.; "Magnetism: an introductory survey", Dover Publications Inc., Mew York (1970).

MYE, M.J.; "Before big Science: The pursuit of Modern Chemistry and Physics, 1800-1940 ", Harvard University Press, Cambridge (1999).

PURRIMGTOM, R.D.; "Physics in the nineteenth century", Rutgers University Press, New Brunswick (1997).

SIMGER, Ch.;"A Short History of Science", Dover Publications Inc., Mew York (1997).

WILLIAMS, L.P; "Michael Faraday", Da Capo Press, Inc., Mew York (1987) 